\title{
A Study on Striped and Checked Patterns in Silk Fabric of the Republic of China (1912-1949)
}

\author{
Xu Zheng ${ }^{1,2}$ \\ ${ }^{1}$ School of Fashion \& Art Design, Donghua University, Shanghai, China \\ ${ }^{2}$ China National Silk Museum, Hangzhou, Zhejiang, China \\ Correspondence: Xu Zheng, China National Silk Museum, 73-1 Yuhuangshan Road, Hangzhou, 310002, \\ Zhejiang, China. Tel: 86-571-8181-9610. E-mail: eastseaxu@gmail.com
}

Received: July 18, 2013 Accepted: August 19, 2013 Online Published: October 29, 2013

doi:10.5539/ass.v9n15p72

URL: http://dx.doi.org/ass.v9n15p72

\begin{abstract}
Based on the analysis and investigation on a large number of striped and checked patterns in silk fabric of the Republic of China (1912-1949) and some relevant historical records, this paper mainly reviews the types of striped and checked patterns in silk fabric of the Republic of China. It also discusses the use of weave design in striped and checked patterns, and points out that striped and checked patterns turned to be one of the most popular patterns in silk fabric during this period, only ranking second to floral pattern. The influence of western design, changes in fashion and technological innovations are main reasons for this transition.
\end{abstract}

Keywords: striped and checked pattern, the Republic of China, silk fabric

\section{Introduction}

Striped and checked patterns, including striped pattern and checked pattern, are one of Chinese traditional patterns in silk fabric, but had never dominated in the long pattern-design history. And in modern times, under the influence of western design ideas, such as Cubism, Abstractionism, Constructivism, etc., and changing aesthetic ideas to women's appearance, striped and checked patterns are diverse and have different forms. And they turned to be one of the most important motifs in silk fabric during this period the Republic of China (1912-1949), only ranking second to floral pattern.

However, differing from the important position striped and checked patterns has occupied in Chinese modern silk fabric, the existing study, such as Development of Modern Textile Motifs in China (Bian, 1997), Emergence and Development of Modern Silk Fabric in China (Bao, 1989), A Study on the Chinese Silk Pattern Among the Areas South of the Yangtze River During the Period of the Republic of Century (Fan, 2010), A Study on the Chinese Silk Pattern of the 20th Century (Wen, 2011), A Research on Shanghai Silk Evolvement from the Design Management System of Meiya Silk Mill during Republic of China (Xu, 2012), etc., emphasize much more on the whole history of modern patterns in silk fabric, merely mentioning striped and checked patterns as a very small part or even neglect it. As some point, there are no such studies specific on striped and checked patterns in silk fabric yet.

Thus, based on the analysis and investigation on a large number of striped and checked patterns in silk fabric of the Republic of China (1912-1949) and some relevant historical records, this paper mainly reviews the history and types of striped and checked patterns in silk fabric of the Republic of China, the reason why they were so popular in modern silk fabrics. And this paper also discusses the relationship between the weave techniques and striped and checked patterns, which is a neglected point of view by existing research, to make a comprehensive study.

\section{The History of Striped and Checked Patterns in Ancient Silk Fabrics}

In ancient Chinese silk fabric striped and checked pattern has already appeared. A document of the Han Dynasty called Shiming shows the earliest records about striped fabric. The fabric was known as Changming damask, in a structure of twill on plain weave, and described as follow: it alternates colors on the whole fabric. Some 4th century striped fabrics, unearthed from Turfan, Xinjiang Region, are the earliest finding. Colored striped pattern was very popular during 5-10th century and it was called Jian in the Tang Dynasty. (Figure 1) In fact, Jian in its original sense is dyeing pattern which looks like iridescence. It is recorded in Shoku Nihongi that "it alternates 
colors on whole piece of fabric. For example, the colors would be arranged like that: white is followed by red, then by dark red, by red, by light blue, by blue, by light blue, by white, and the like, which appear as halos around the Sun, so the piece of fabric is named as Yunjian, and later as Jin", and other names like Great Jianjin (means jin-silk with striped pattern), etc., also can be seen in such written records of contemporaries. In the Song Dynasty, a new type of colored striped pattern called Jian Dao was appeared, Jian means alternating in different colors, and Dao means stripe. Compared with Jian, Jiandao is a kind of colorful striped pattern arranged by warp yarns of different colors. There is a record in Menglianglu of Song Dynasty that "Zhusi (stain and stain damask) include Zhijin (gold brocade), Jiandao, Shanhe (shining satin), etc."

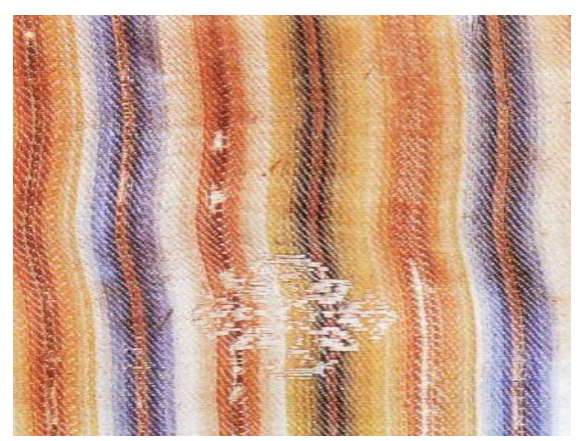

Figure 1. Twill damask with striped pattern, Tang Dynasty, unearthed from Astana, Turfan, Xinjiang

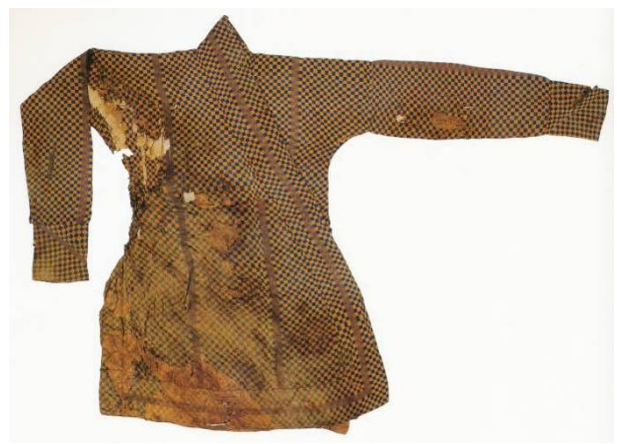

Figure 2. Jin-silk caftan with checked pattern, Han and Jin Dynasty, unearthed from Niya, Xinjiang

Checked pattern was called $Q i$ or checkerboard pattern. The earliest record about checked fabric also appears in Shiming, a document of the Han Dynasty. And some checked fabrics of the Wei and Jin Dynasty were unearthed from Huahai, Gansu Province. At that time, checked pattern was created by interweaving the warp yarn and the weft yarn. (Figure 2) For example, there is a Tang vamp unearthed from Turfan, Xinjiang Region, whose colorful warps yarns and weft yarns can be arranged and weaved into sixteen checked patterns of different colors.

Since then, silk fabric with striped and checked pattern in various terms was produced in every Dynasty, such as Huihui brocade, Yuehua brocade, Yun brocade, etc. But in traditional silk fabric, "patterns should be of meaning, and meanings should be auspicious", thus striped and checked patterns had never become a major motif until modern times.

\section{The Epidemic of Striped and Checked Patterns in Modern Silk Fabrics}

But in the Republic of China (1912-1949), especially in the 1930s, striped and checked pattern in silk fabric increased dramatically. In the collection of Academy of Art and Design, Tsinghua University, there are some silk fabrics of the 1930s. Among these collections, there are 21 fabrics with striped and checked pattern, accounting for $26 \%$ of total. And $54 \%$ of the collections are fabrics with floral pattern. Striped and checked pattern ranks second only to floral pattern as the most important and basic pattern of silk fabric. (Figure 3) Main reasons for the change are as follow: 


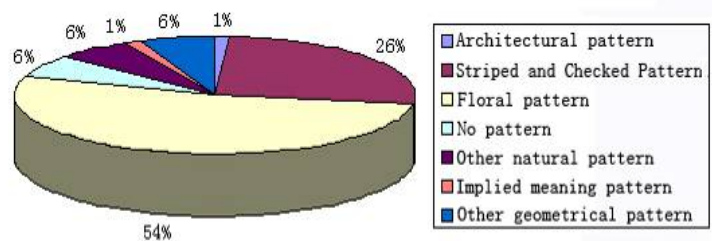

Figure 3. The proportion of patterns in silk fabrics of the 1930s collected in academy of art and design, Tsinghua University

Firstly, it is due to the influence of western design. In contrast with China, traditionally, striped and checked pattern was unpopular in the West, stripes was even seen as a symbol of social crime, devil and prostitute. But in the early 20th century, with the prevalence of cubism, abstract expression and constructivism, the meaning of pattern was no longer important in design. Thus the traditional prejudice against striped and checked pattern was broken. From then on, striped and checked pattern was used extensively in clothing fabric (Figure 4), and became more and more important. That striped and checked patterns were popular in western countries facilitated the use of striped and checked patterns in modern Chinese silk fabric. On the one hand, as China opened itself to the world, a large number of exotic fabrics with striped and checked patterns dumping, popularizing this kind of pattern in China. Lee Yuyi, an art critic lived at that time, had a description of fashion in early period of Republic of China that "because of Russian cloth introducing, then striped patterns become favored." On the other hand, as many students who went to Europe and the United States in 1930s for dyeing and designing study come back to China and engaged in pattern design in silk fabric, the influence of western design ideas has deepened, and a large number of striped and checked patterns in silk fabric of western style have been designed. (Figure 5)

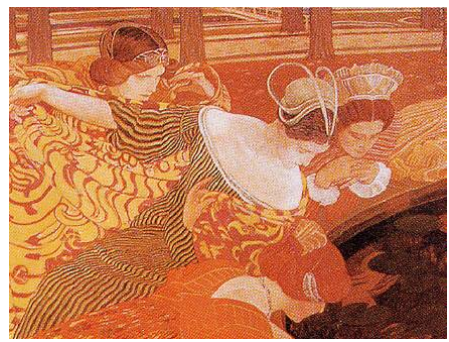

Figure 4. Striped and checked pattern used in clothing fabric

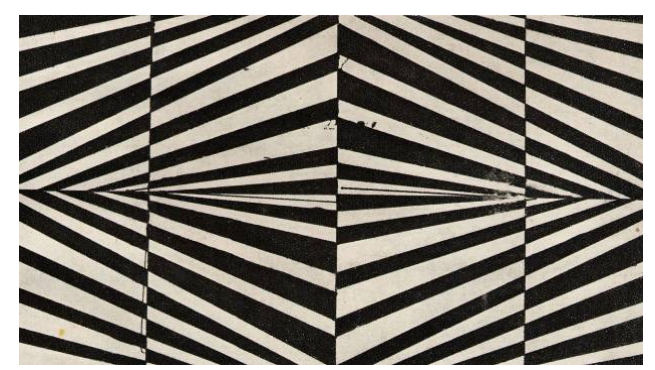

Figure 5. Striped and checked pattern in silk fabric designed by the returned students from Europe and the United States, 1930-1940s

Another reason why striped and checked patterns were popular in modern China are that Chinese clothing system has been reformed in the early period of Republic of China and as well as western styles have been introduced and accepted. It is typical in women's clothing. Since Chinese traditional clothing tend to cut plane, the regular striped and checked patterns on wide, straight clothes turn out to be dull, so it would not be used in traditional clothing much; while in western-style clothing with three-dimensional cuttings, striped and checked patterns are perfect for ideal motif image-building, especially for the improved cheongsam. (Figure 6) Because not only vertical stripes can help to make the body looking to be slender, but also the striped and checked pattern on cheongsam will change into a curve effect when cheongsam is on the female body, which can flatter female's 
beautiful figure. (Figure 7) On the other hand, the status of Chinese women has been advanced in modern time, leading to a preference of brief, three-dimensional style of the silk fabric pattern. Compared with complex floral pattern, striped and checked pattern is simpler, steadier and also with subtle variances. It can help to highlight female's quiet and elegant temperament. So striped and checked pattern is well acclaimed, which has been proven by a large number of old photos. (Figure 8 )

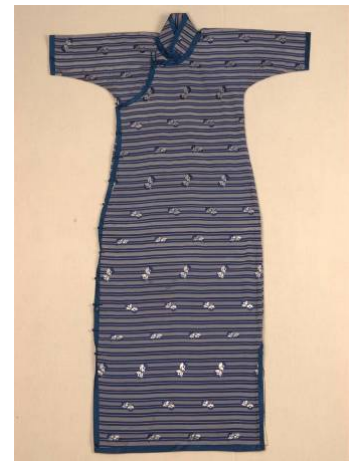

Figure 6. Cheongsam with checked pattern, 1930s, collected by China National Silk Museum

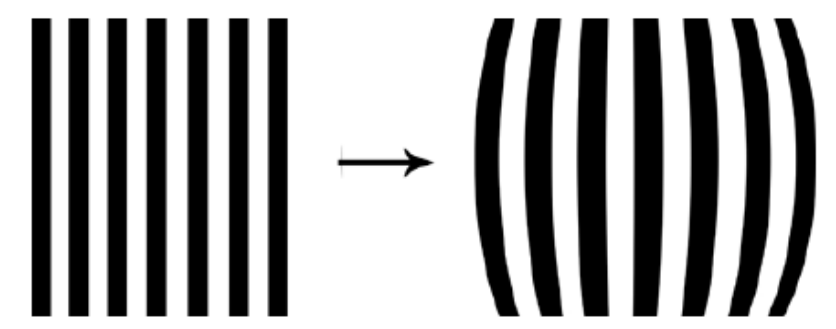

Figure 7. A before-and-after comparison of the striped pattern used in cheongsam fabric

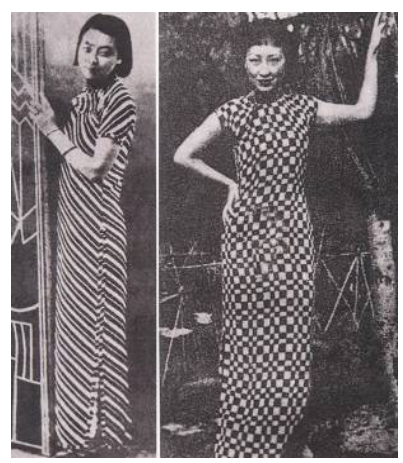

Figure 8. Cheongsam with striped and checked pattern, 1930s

In addition, the technical development also contributes a lot in facilitating striped and checked patterns in modern silk fabrics. As traditional weaving looms were totally operated by human, it is difficult to straighten and neaten the striped and checked patterns; while modern weaving machines, especially Jacquard loom, with mechanization or semi-mechanization can perfect the pattern. Another reason is the change of fabric's weave structure. Traditional striped and checked pattern usually appeared in heavy fabrics such as brocade, but in modern times, striped and checked pattern often adopted by light fabrics such as crepe, satin and gauze, which are much easier than brocade in weave structure and can create varied appearance even by slightly changing the arrangement of warps and wefts. Therefore, it save more time and reduce more cost to produce striped and checked fabrics in modern times. Meanwhile, the quality of striped and checked fabrics is more exquisite than traditional fabrics because of using automated loom and filature silk and other new materials; and cconsumers can buy silk fabrics of good quality and with attractive appearance at a relatively lower price. These all make silk fabrics with striped and checked pattern become widely favored in the Republic of China. This is also the reason why striped and checked patterns were still popular in depressive 1940s. (Figure 9) 


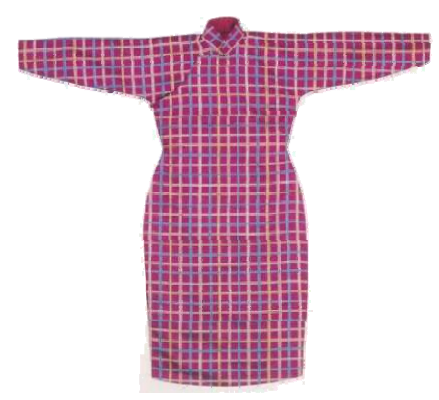

Figure 9. Cheongsam with checked pattern, 1940s, collected by Taiwan SOKA association

Therefore, so to speak, there are several factors leading to the popularizing of striped and checked patterns in modern silk fabric: western dyeing, weaving, and design ideas, the modern Chinese clothing reform, western-style clothing popular in China, silk weaving technical development, etc.

\section{Categories of Striped and Checked Pattern}

As the comprehensive result of above-mentioned elements, during this period, striped and checked patterns become more flexible in design, more abundant in variety, and more beautiful in appearance. And based on the analysis and investigation on a large number of striped and checked patterns in silk fabric, we can see that these patterns are mainly formed by stripes; however, the stripes can be different in thickness, interval and color, and it also can combine with other patterns. Generally, it can be divided into the following categories.

\subsection{Striped Pattern}

Striped pattern mainly includes vertical stripe, horizontal stripe, oblique stripe, wavy stripe and others. Vertical stripe and horizontal stripe are formed by warps or wefts in different colors. They are simple to produce therefore fabric with these stripes is relatively inexpensive. Striped pattern can be created with warps and wefts in same color but using different weave structures (Figure 10). Silk produced by the Hangzhou Zhendan silk factory in the 1930s (Figure 11) is an excellent example of striped silk with complex color scheme. It shows stripes in the interval arrangement of light blue, black, white, orange, yellow, red and other colors of different thickness. Oblique striped pattern can be divided into two groups according to the stripes in the same direction or different direction (Figure 12).

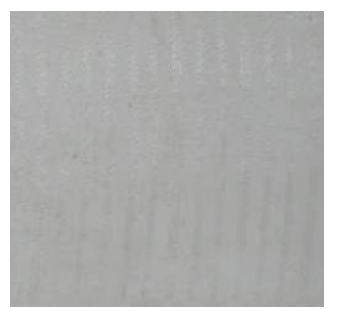

Figure 10. Monochrome vertical striped silk, 1940s, collected by academy of art and design, Tsinghua University

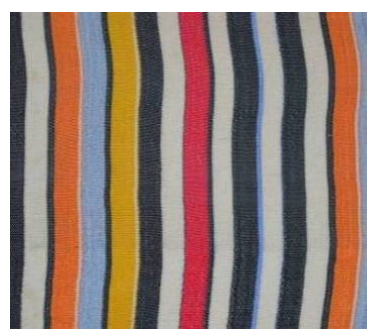

Figure 11. Colored vertical striped silk, 1930s, collected by academy of art and design, Tsinghua University 


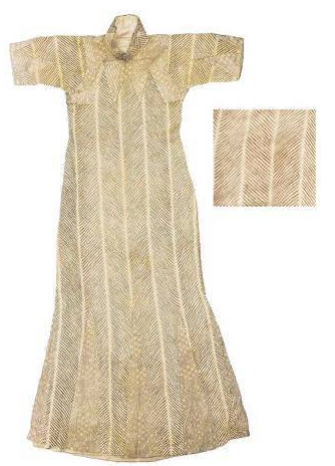

Figure 12. Cheongsam with stripes in the different direction, 1930s, collected by China National Silk Museum

Wavy striped pattern includes pattern formed by polygonal lines and pattern created with curves. An example of the former is zigzag pattern, being formed by continuous polygonal lines and showing a lot of shrill acute angles (Figure 13). The curves can be single, parallel or a continuous curve bending back on itself. They are smooth, lively and varied (Figure 14). Some patterns are very complex, with curves interweaved, overlaid or combined. As it is shown in Figure 15, some complex curves, of varied thickness, interlace irregularly and form the pattern. It seems to be messy, but full of charm.

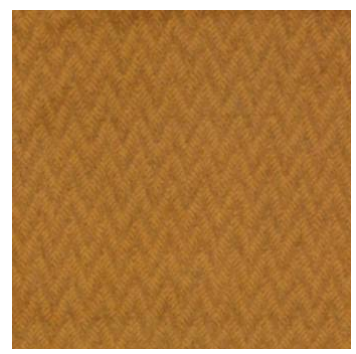

Figure 13. Silk with zigzag pattern, 1940s, collected by China National Silk Museum

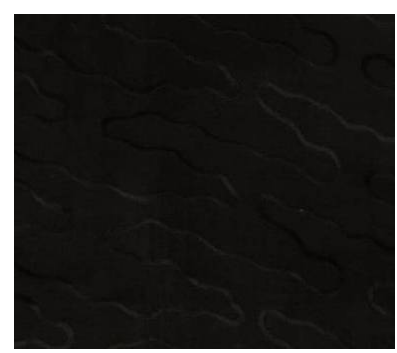

Figure 14. Silk with a single curve, 1930s, collected by China National Silk Museum

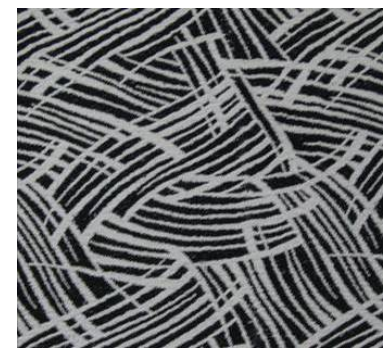

Figure 15. Silk with complex curves, 1930s, collected by academy of art and design, Tsinghua University 


\subsection{Checked Pattern}

Compared with striped pattern, checked pattern are more diverse. Generally, it can be divided into uniform checked pattern and non-uniform ones. Uniform checked pattern has the feature, that the size and content of each grid are the same. It can be produced by following methods. Firstly, as it is shown in Figure 16-A, vertical and horizontal stripes, of same thickness, intersect to form checks or diamonds. There are clear lines between checks. By using stripes in different colors can enhance changes in the pattern. Secondly, as it is shown in Figure 16-B, checks or diamonds in the same size and different colors are alternately arranged. And there are no clear lines between checks. If the colors of checks or diamonds are the same, the checked effect also can be created by using different weaves, which have different refractive index of light. Thirdly, as it is shown in Figure 16-C, there are no checks or diamonds, but the fabric shows a checked effect by using different patterns or textures in neighboring areas.

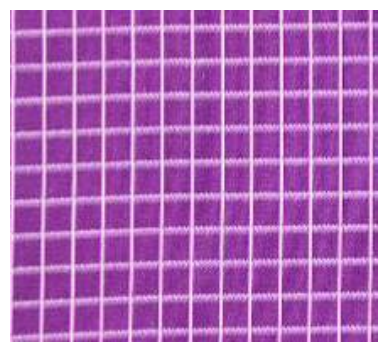

Figure 16-A

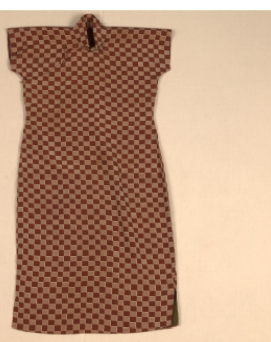

Figure 16-B

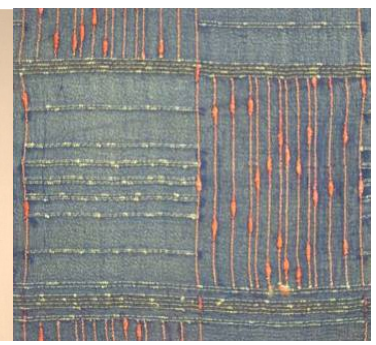

Figure 16-C

Figure 16. Uniform checked pattern in different forms, 1930-1940s (Figure 16-A and C are collected by academy of art and design, Tsinghua University, 16-B is collected by China National Silk Museum)

Non-uniform checked pattern has the feature, that the size and content of each check are not the same. The methods of creating non-uniform checked pattern are similar to those of uniform checked pattern. But the size and arrangement of checks are more variable (Figure 17). Generally, non-uniform checked pattern is freer and more artistic, while uniform checked pattern is more rigorous.

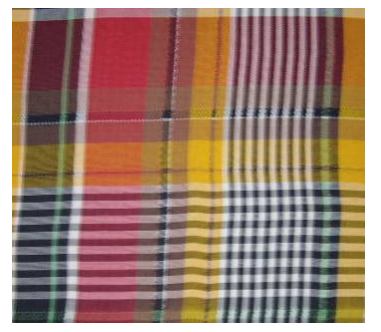

Figure 17. Silk with non-uniform checked pattern, 1940s, collected by academy of art and design, Tsinghua University

\subsection{Compound Striped and Checked Pattern}

Though striped and checked pattern mostly consists of simple stripes, checks or other geometric elements; there are still some patterns combining stripes or checks with other elements, such as floral or animal motives. This kind of pattern is called compound striped and checked pattern in this paper. Its combinations generally have the following categories.

The first one is using striped and checked pattern as grid then filled with small geometric pattern or floral pattern, or simply getting floral pattern in a continuous linear arrangement. The way of filling small pattern, such as floral or animal pattern, in striped and checked grid was also adopted by ancient silk fabric For example, a piece of $j i n$-silk of the Northern Dynasty shows a pattern of filling beasts in checks (Figure 18). The only difference between animal pattern in checks in ancient fabric and modern silk is that the beast is replaced by a naive cartoon animal (Figure 19). And the design of filling florets in between stripes (Figure 20) can be considered as an inheritance of the floral pattern in stripes in jin-silk of the Tang dynasty (Figure 21) 


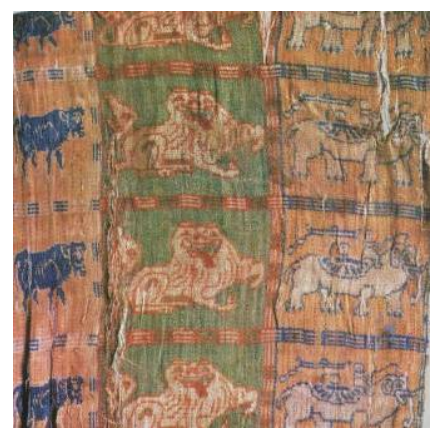

Figure 18. Jin-silk with animal in checked pattern, Northern Dynasty, unearthed from Astana, Turfan, Xinjiang

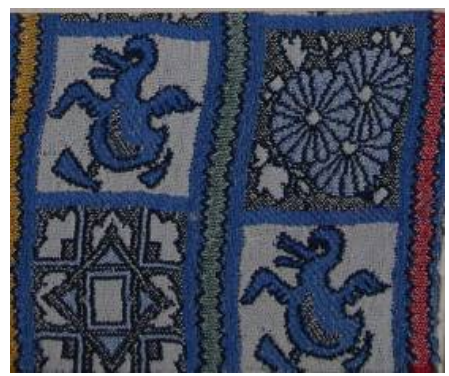

Figure 19. Crepe with a cartoon animal in checked pattern, 1940s, collected in academy of art and design, Tsinghua University

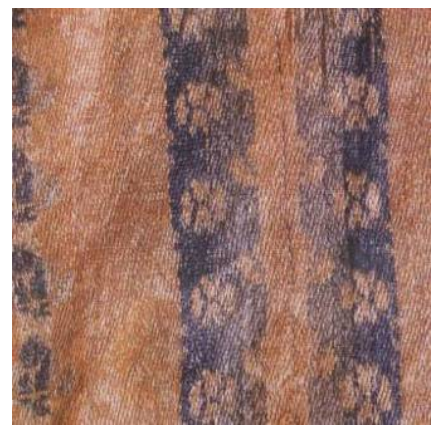

Figure 20. Jin-silk with floral in striped pattern, Tang Dynasty, unearthed from Reshui, Dulan, Qinghai

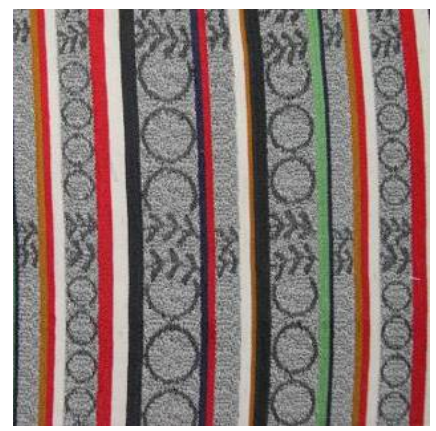

Figure 21. Crepe with floral in striped pattern, 1930s, collected by academy of art and design, Tsinghua University

The second one is using the striped and checked pattern as ground on which to add flowers, animals and other elements. In this way, the pattern seems to be on two layers, and it is similar to the pattern on Tianhua Brocade of the Ming and Qing Dynasties. But there is also difference between them. The pattern in such traditional brocade always combines swastika with peony or dragon to indicate eternal wealth (Figure 22). However, decorativeness is the primary purpose of the pattern in modern period, it doesn't have much auspicious meanings (Figure 23). 
The third one is out of the frame limitation of striped and checked pattern. It chooses flower, animal, and other elements as the main pattern, and striped and checked pattern formed by weaving as the ground. Compared with the first type, the flower, animal and other elements are not limited in between stripes or in checks, but freely repeat in the whole fabric. Compared with the second type, there is no obvious pattern as ground. The focus of the third type is to make the pattern abundant in color, rather than to make the pattern seem to be on more layers (Figure 24).

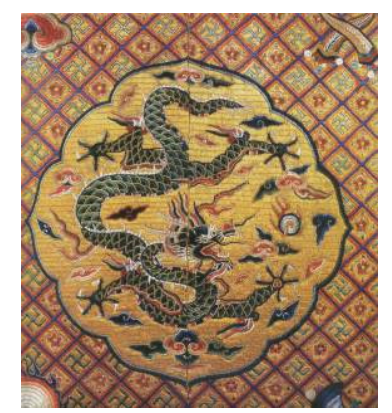

Figure 22. Brocade with dragon roundel on checked pattern ground, Ming Dynasty, private collection

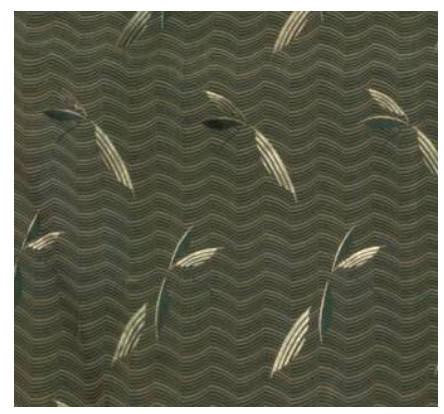

Figure 23. Satin with leaves on striped pattern ground, 1930s, collected by China National Silk Museum

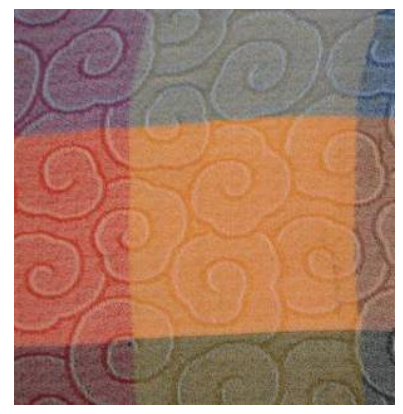

Figure 24. Crepe with compound striped and checked pattern, 1940s, collected by academy of art and design, Tsinghua University

\section{Relationship between Weaving Techniques and Pattern Design}

The biggest feature of striped and checked pattern design in modern silk fabric is its relationship with weaving techniques. Compared with floral, animal and other motifs which depend largely on graphic design, striped and checked patterns are mainly decided by the arrangement of warp yarns and weft yarns, and such.

Using colored warps and wefts is the most common way to form striped and checked pattern. Generally, you can get vertical (or horizontal) stripes by interweaving colored warps (or wefts) with monochrome wefts (or warps). And interweaving colored warps with colored wefts can get checked pattern (Table 1). Meanwhile, the arrangement of colored warps and wefts is varied. If the arrangements of every colored yarn are the same, it can be called single-type colored yarns arrangement, such as two black warps followed by two white warps and repeat. Compound-type colored yarns arrangement is another form which has no less than two kinds of colored yarns arrangement, such as two black warps followed by two white warps, then one black warp fallowed by one 
white warp. ${ }^{[3]}$ Uniform striped and checked pattern can be formed by using single-type colored yarns arrangement (Figure 25), while striped and checked patterns with abundant changes can be created by using compound-type colored yarns arrangement (Figure 26).

Table 1. Effects of using colored warps and wefts in the there-elementary weaves

\begin{tabular}{|c|c|c|c|c|c|}
\hline & Plain weave & Warp twill & Weft twill & Warp satin & Weft satin \\
\hline $\begin{array}{l}\text { Colored } \\
\text { warps }\end{array}$ & $\begin{array}{l}\text { Vertical striped } \\
\text { pattern }\end{array}$ & $\begin{array}{l}\text { Vertical striped } \\
\text { pattern }\end{array}$ & & $\begin{array}{l}\text { Vertical striped } \\
\text { pattern }\end{array}$ & \\
\hline $\begin{array}{l}\text { Colored } \\
\text { wefts }\end{array}$ & $\begin{array}{l}\text { Horizontal } \\
\text { striped pattern }\end{array}$ & & $\begin{array}{l}\text { Horizontal striped } \\
\text { pattern }\end{array}$ & & $\begin{array}{l}\text { Horizontal } \\
\text { striped pattern }\end{array}$ \\
\hline $\begin{array}{l}\text { Colored } \\
\text { warps and } \\
\text { wefts }\end{array}$ & $\begin{array}{l}\text { Striped and } \\
\text { checked pattern }\end{array}$ & $\begin{array}{l}\text { Striped and } \\
\text { checked pattern }\end{array}$ & $\begin{array}{l}\text { Striped and } \\
\text { checked pattern }\end{array}$ & $\begin{array}{l}\text { Striped and } \\
\text { checked pattern }\end{array}$ & $\begin{array}{l}\text { Striped and } \\
\text { checked pattern }\end{array}$ \\
\hline
\end{tabular}

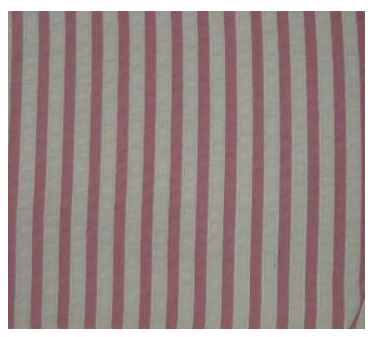

Figure 25. Striped fabric using single-type colored yarns arrangement, 1940s, collected by academy of art and design, Tsinghua University

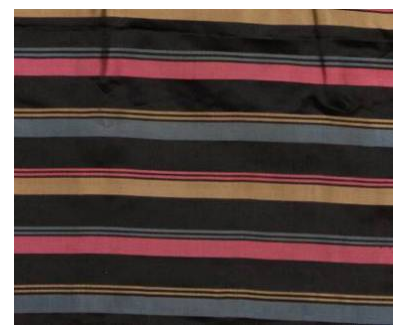

Figure 26. Striped fabric using compound-type colored yarns arrangement, 1940s, collected by China National Silk Museum

Striped and checked pattern can also be created by slight changes in warps and wefts, including changes in thickness, appearance, twist and twist direction. It is also an important method. Figure 27 shows a fabric using fancy yarns to form striped pattern. Figure 28 shows a fabric using additional -warps weaving technology to form checked pattern. The redundant warps on the back of the fabric can be cut off.

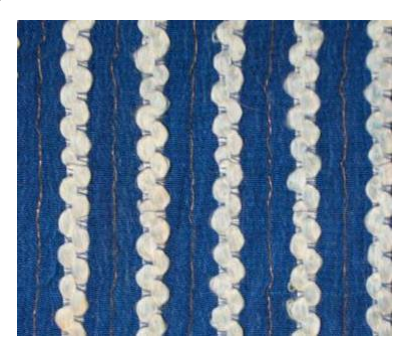

Figure 27. Striped fabric using fancy yarns, 1930s, collected by academy of art and design, Tsinghua University 


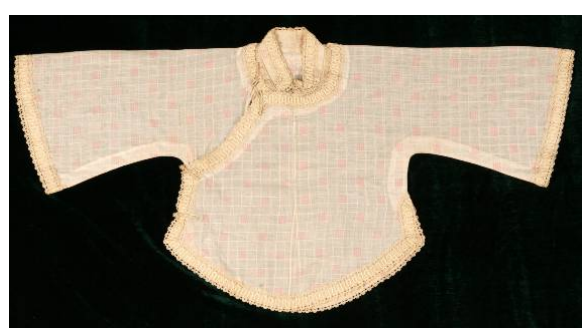

Figure 28. Checked fabric additional-warps weaving technology, 1920s, collected by China National Silk Museum

Another important way to form striped and checked pattern is to take the advantage of different weave structure and washing shrinkage of different fabric is. The method of weave design is very diverse. A common method is to alternate different weave structures in monolayer fabric. A fabric with stripes created by alternating satin weave structure and gauze weave structure is showed in Figure 29-A. Figure 29-B shows a fabric in a double-layer weave structure with checks created by two groups of warps and wefts respectively woven in plain weave in different areas, and after scouring and dyeing, the pattern is more vivid and shows a special texture effect because the shrinkage of warps and wefts is different. The fabric in Figure 29-C shows a special visual effect, bearing vertical colored stripes intersected with oblique sliver-colored stripes. The colored stripes are created by warps in different colors woven in satin weave structure, and the sliver-colored stripes are formed by sliver-colored wefts appearing in partial areas.

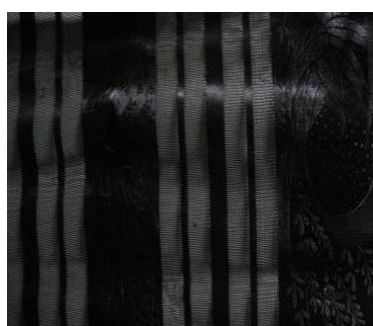

Figure 29-A

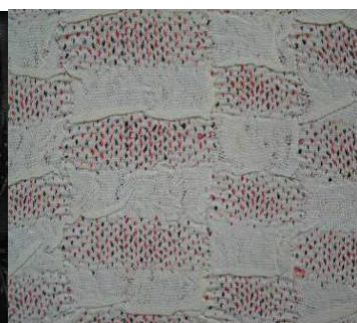

Figure 29-B

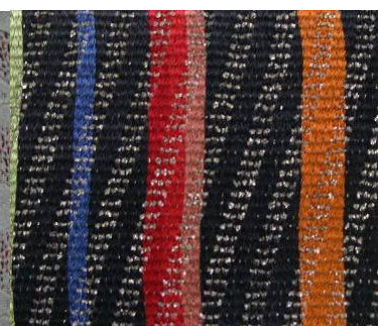

Figure 29-C

Figure 29. Striped and checked fabric with pattern created by different weave structure, 1920-1940s, (Figure 29-A is collected in China National Silk Museum, Figure 29-B and C are collected in academy of art and design, Tsinghua University)

\section{Conclusion}

In summary, several characteristics of striped and checked patterns in Chinese modern silk fabric are as follows:

Firstly, although striped and checked patterns have been used in silk fabric for quite a long time, because of weaving techniques, auspicious meanings and other factors, they had not dominated the pattern world. And under the influence of western dyeing, weaving, and design ideas, the modern Chinese clothing reform, western-style clothing popular in China, silk weaving technical development, and so forth, striped and checked patterns began to popularize in early period of Republic of China, and reached its peak in 1930s-1940s, rapidly turning to be one of the most popular patterns in silk fabric during this period, only ranking second to floral pattern.

Secondly, striped and checked pattern used in modern silk fabric is not a simple continuation of that in Chinese ancient fabric. It is more flexible in design, more abundant in variety, and more beautiful in appearance. There are differences between striped and checked patterns in modern silk fabric and that in traditional silk fabric: (a) the former is purely for decorative use, with dominative beauty purpose and few symbolic meanings, while the latter focuses auspicious meanings; (b) the former varies, and be pleasing to the eye is the primary criterion; while the latter is more stylized, with a strong national identity. Thus, besides the traditional part, striped and checked patterns in modern silk fabric have included the western aesthetic philosophy and Modernism thoughts, and created a large number of new styles. This is a very important phenomenon in the development of the patterns of modern silk fabric.

Thirdly, compared with floral, animal and other motifs which depend largely on graphic design, striped and 
checked patterns closely relate to weaving techniques. Changing kinds, colors, arrangements of warp yarns and weft yarns is the way to get different kinds of striped and checked patterns. Weaving techniques become one of the most critical factors of the whole exterior effects of striped and checked patterns. There are no such patterns with so many design ways for just one pattern ever, which also reflects how popular striped and checked patterns were at that time.

As such, as the competitiveness of design today relies more and more on the advantage of cultural resources, the striped and checked patterns from the Republican period, as a treasury of rich motifs and numerous forms, can provide profound inspirations for contemporary Chinese design. In fact, confronted with the changing consumer tastes, those striped and checked patterns continue to show their vitality today. Therefore, the exploration and study on striped and checked patterns design during this period will help with the summarization of ways and experiences that can be inherited and used today, leading to the enhancement of silk pattern design levels.

\section{References}

Bao, M. X. (1985). The origin and development of jiandao. Silk, 6, 6-8.

Bao, M. X. (1989). Emergence and development of modern silk fabric in China. Journal of China Textile University, 1, 59-65.

Bian, X. Y. (1997). Development of modern textile motifs in China. Journal of China Textile University, 6, 96-101.

Cheng, Y. F. (2002). The difference between east patterns and west patterns. Beijing: China Textile \& Apparel Press.

Fan, Y. (2010). A study on the Chinese silk pattern among the areas south of the Yangtze River during the period of the Republic of Century. Nanjing: Nanjing University of the Arts.

Li, Y. Y. (1972). Decorations of Chinese metropolis from 1900 to 1925. Taipei: Zhongshan Publishing House.

Tao, S. P. (1947). Practical weaving science. Shanghai: Zhonghua Book Company.

Wen, R. (2011). A study on the Chinese silk pattern of the 20th century. Suzhou: Suzhou University.

$\mathrm{Xu}, \mathrm{L}$. (2012). A research on Shanghai silk evolvement from the design management system of Meiya silk mill during Republic of China. Hangzhou: Chinese Academy of the Art.

Zhao, F. (2005a). A history of Chinese silk art. Beijing: Cultural Relics Publishing House.

Zhao, F. (2005b). The General History of Chinese Silk. Suzhou: Suzhou University Press.

\section{Copyrights}

Copyright for this article is retained by the author(s), with first publication rights granted to the journal.

This is an open-access article distributed under the terms and conditions of the Creative Commons Attribution license (http://creativecommons.org/licenses/by/3.0/). 